\title{
Efficacy and Safety of Etomidate in Comparison with Propofol or Midazolam as Sedative for Upper Gastrointestinal Endoscopy
}

\author{
Jae Hyun Kim*, Sanghwan Byun*, Youn Jung Choi, Hye Jung Kwon, Kyoungwon Jung, Sung Eun Kim, Moo In Park, Won Moon \\ and Seun Ja Park \\ Department of Internal Medicine, Kosin University College of Medicine, Busan, Korea
}

Background/Aims: In this study, we compared the efficacy and safety of etomidate with those of propofol or midazolam for the maintenance of sedation during endoscopy.

Methods: The study enrolled patients who underwent sedative endoscopy in our hospital and divided them into three groups. Patients in each group were administered midazolam as induction therapy and were subsequently administered either midazolam ( $\mathrm{M}+\mathrm{M}$ group), propofol $(\mathrm{M}+\mathrm{P}$ group), or etomidate $(\mathrm{M}+\mathrm{E}$ group) as maintenance medication. The primary outcome was overall cardiovascular and respiratory adverse events.

Results: In total, 105 patients who underwent sedative endoscopic examination were enrolled. The outcomes related to the procedure and sedation were not significantly different among the groups. Overall cardiovascular and respiratory adverse events were observed in 9 patients (25.7\%) in the $\mathrm{M}+\mathrm{M}$ group, 8 patients (23.5\%) in the $\mathrm{M}+\mathrm{P}$ group, and 10 patients (27.8\%) in the $\mathrm{M}+\mathrm{E}$ group. The logistic regression analysis revealed that etomidate use was not an independent risk factor for overall cardiovascular and respiratory adverse events.

Conclusions: The outcomes following the use of etomidate for maintenance after induction with midazolam for sedation in upper gastrointestinal endoscopy were not inferior to those following midazolam or propofol use from the perspectives of safety and efficacy. Clin Endosc 2020;53:555-561

Key Words: Endoscopy; Etomidate; Midazolam; Propofol; Sedative

\section{INTRODUCTION}

Sedative endoscopy can minimize patient discomfort during endoscopic examination and allows the endoscopist to perform an accurate examination in a stable state. ${ }^{1,2}$ Midazolam and propofol are the most commonly used drugs for sedative endoscopic examination worldwide. According to a

Received: November 6, 2019 Revised: February 4, 2020

Accepted: February 4, 2020

Correspondence: Seun Ja Park

Department of Internal Medicine, Kosin University College of Medicine, 262 Gamcheon-ro, Seo-gu, Busan 49267, Korea

Tel: +82-51-990-5061, Fax: +82-51-990-5055, E-mail: parksj6406@daum.net ORCID: https://orcid.org/0000-0003-3217-5115

*These authors contributed equally to this study.

(c) This is an Open Access article distributed under the terms of the Creative Commons Attribution Non-Commercial License (http://creativecommons.org/ licenses/by-nc/3.0) which permits unrestricted non-commercial use, distribution, and reproduction in any medium, provided the original work is properly cited.
2006 survey of 1,353 endoscopists in the United States, 75\% used midazolam for sedative endoscopic examinations, and approximately $25 \%$ used propofol. ${ }^{3}$ In a 2013 survey of 741 endoscopists in Germany, propofol was the most commonly used sedative for endoscopic examination. ${ }^{4}$

Etomidate is a compound containing a carboxylated imidazole and is commonly used as a sedative for airway intubation in patients with a high risk of hemodynamic compromise. ${ }^{5}$ The drug has a rapid onset time, lasts for 3-5 minutes, is metabolized in the liver, and $75 \%$ of the dose is excreted in the urine. Etomidate induces limited vascular pain upon injection and presents a low risk of respiratory depression and hypotension. ${ }^{6}$ The main adverse effect is myoclonus onset, caused by subcortical disinhibition, which occurs in $20 \%$ to $45 \%$ of patients after administration; however, magnesium sulfate or a small initial dose $(1 \mathrm{mg})$ of etomidate may be helpful to reduce this occurrence. ${ }^{7.8}$ Given its short duration of action, etomidate is considered effective when used in combination with midaz- 
olam. ${ }^{5}$

Midazolam is an imidazole benzodiazepine that has a sedative effect with a fast onset time and a short half-life when injected intravenously; few adverse effects occur and they are able to be controlled by the antagonist flumazenil. ${ }^{9}$ The main adverse effects of midazolam are changes in vital signs, including blood pressure and pulse rate, and respiratory inhibition, which may lead to death. ${ }^{10}$ Paradoxical reactions, such as anxiety, disability, and violent behavior, may also occur after midazolam administration. As a long recovery time is necessary after midazolam administration (elimination half-life: 1.7-2.6 $\mathrm{hr}$ ), it is not easy to administer it in a hospital without a recovery room. Propofol (2,6-diisopropofol) is a phenolic derivative with satisfactory sedative and amnesic properties, an early onset of action, and high metabolic clearance; further, its recovery time is short. ${ }^{11}$ The main adverse effects of propofol are hypotension, respiratory depression, and vascular pain upon injection. ${ }^{12}$ Especially, given that administration of propofol can cause respiratory arrest, monitoring of oxygen saturation is vital. ${ }^{13,14}$ In recent years, cases of mental dependence on propofol have been reported, and the abuse of propofol has emerged as a social problem. ${ }^{15}$ Owing to these adverse effects of midazolam and propofol, there is a growing interest in the identification of more effective and safe sedatives.

In recent research, approaches such as balanced propofol sedation (propofol in combination with midazolam and meperidine) have been tested to achieve more effective and safe endoscopy. ${ }^{16-18}$ Further, several studies have indicated that etomidate-based sedation has the potential for effective and safe endoscopic examination. ${ }^{19-21}$ In the present study, we hypothesized that use of etomidate with midazolam could achieve effective and safe sedation. Given the short duration and the known adverse events, including myoclonus, we did not consider etomidate as an induction therapy, but only as a maintenance medication in sedative endoscopy. Therefore, we sought to compare the efficacy and safety of etomidate to propofol or midazolam for maintenance of sedation during upper gastrointestinal endoscopy.

\section{MATERIALS AND METHODS}

\section{Patients}

This was a retrospective study that analyzed prospectively collected data. Patients between 20 and 75 years of age, classified as American Society of Anesthesiologists (ASA) status I or II who were undergoing sedative endoscopic examination for a health checkup at Kosin University Gospel Hospital in Korea were included. Patients with a history of adverse effects during a previous examination, chronic kidney disease, liver cirrhosis, heart failure, or sleep apnea, or who were taking medicines that interact with midazolam, propofol, or etomidate were excluded. Detailed clinical data on age, sex, height, weight, body mass index (BMI), comorbidities, and histories of smoking and alcohol were collected. This study was approved by the Institutional Review Board of Kosin University Gospel Hospital (KUGH 2019-08-017).

\section{Grouping and sedation}

Included patients were divided into three groups by using a table of random numbers. All patients were administered midazolam $0.05 \mathrm{mg} / \mathrm{kg}(0.03 \mathrm{mg} / \mathrm{kg}$ if $\geq 65$ years of age $)$ as induction therapy by endoscopists. Subsequently, additional midazolam $0.03 \mathrm{mg} / \mathrm{kg}(0.015 \mathrm{mg} / \mathrm{kg}$ if $\geq 65$ years of age $)$ in the $\mathrm{M}$ + M group, propofol (Freefol-MCT, $120 \mathrm{mg} / 12 \mathrm{~mL}$; Daewon Pharmaceutical Co., Ltd., Seoul, Korea) $0.3 \mathrm{mg} / \mathrm{kg}(0.15 \mathrm{mg} /$ $\mathrm{kg}$ if $\geq 65$ years of age) in the $\mathrm{M}+\mathrm{P}$ group, or etomidate (Etomidate Lipuro, $20 \mathrm{mg} / 10 \mathrm{~mL} / \mathrm{A}$; B. Braun Korea, Seoul, Korea) $0.075 \mathrm{mg} / \mathrm{kg}(0.035 \mathrm{mg} / \mathrm{kg}$, if $\geq 65$ years of age $)$ in the $\mathrm{M}+\mathrm{E}$ group were administered as maintenance medications. In the $\mathrm{M}+\mathrm{E}$ group, before administration of the maintenance dose, an initial dose of etomidate $1 \mathrm{mg}$ was given to identify any adverse effects, such as myoclonus.

\section{Endoscopic procedures and recovery}

All endoscopic examinations were performed by two experienced endoscopists (YJC and HJK). Prior to sedation, baseline vital signs of blood pressure, heart rate (HR), and $\mathrm{O}_{2}$ saturation of all patients were recorded by a well-trained nurse. During endoscopic examination, the vital signs of all patients were additionally recorded every 2 minutes, and all patients were monitored for onset of adverse effects. Time to sedation induction, total procedure time, and repeated number and doses of maintenance sedative were also assessed. After completion of the endoscopic examination, patients were transferred to a separate recovery room where a recovery room nurse measured their vital signs, recovery time, and the satisfaction of both the patients and endoscopists.

\section{Study outcomes and definition}

The primary outcome was overall cardiovascular and respiratory adverse events including transient hypotension, bradycardia, tachycardia, respiratory depression, oxygen desaturation, and arrhythmia. The secondary outcome was the comparison between groups of time to sedation, total procedure time, recovery time, repeated number and doses of maintenance sedatives, and satisfaction of patients and endoscopists. Adverse effects other than cardiopulmonary events were also evaluated.

Major adverse events were defined as endotracheal intuba- 
tion, permanent neurologic impairment, or death. Hypotension was defined as a decrease of more than $20 \%$ from baseline or a systolic blood pressure of less than $90 \mathrm{~mm} \mathrm{Hg}$. Bradycardia and tachycardia were defined as HR of $<50$ beats/min and $>100$ beats/min, respectively. Respiratory depression was defined as a respiration rate of $<10$ breaths/min, whereas oxygen desaturation was defined as $\mathrm{O}_{2}$ saturation $<90 \%$.

In addition, we defined the time to sedation as the time interval between the initial administration of sedative and insertion of the endoscope. Total procedure time was defined as the time interval from insertion to removal of the endoscope. Recovery time was defined as the time interval between removal of the endoscope and the patient reaching a fully awakened state (Aldrete score of 10). After completion of the endoscopic examination, a recovery room nurse asked patients to indicate their satisfaction by using a short questionnaire with a visual analog scale (score range from zero to 10 points; 0 points = not at all satisfied and 10 points = absolutely satisfied). Endoscopists also recorded their satisfaction with the examination by using a short questionnaire with a visual analog scale (score range from zero to 10 points; 0 points $=$ not at all satisfied and 10 points $=$ absolutely satisfied).

\section{Statistical analysis}

Student's $t$-test and chi-square test were performed for continuous and categorical variables, as appropriate. Continuous data with normal distributions were expressed as the mean \pm standard deviation, whereas categorical data are presented as the number of subjects (\%). To analyze the factors associated with adverse events related to sedation, multivariate logistic regression analysis was performed, with $p$-values of $<0.05$ considered to be statistically significant. Statistical analyses were performed using the Statistical Package for the Social Sciences version 24.0 software program (IBM Co., Armonk, NY, USA).

Table 1. Baseline Characteristics

\begin{tabular}{|c|c|c|c|c|}
\hline & $\begin{array}{c}M+M \text { group } \\
(n=35)\end{array}$ & $\begin{array}{c}M+P \text { group } \\
(n=34)\end{array}$ & $\begin{array}{c}M+\text { E group } \\
(n=36)\end{array}$ & $p$-value \\
\hline Age $(y r)$, mean $\pm S D$ & $54.8 \pm 8.3$ & $56.1 \pm 5.6$ & $55.1 \pm 6.5$ & 0.729 \\
\hline Sex, $n(\%)$ & & & & 0.666 \\
\hline Male & $17(48.6)$ & $13(38.2)$ & $17(47.2)$ & \\
\hline Female & $18(51.4)$ & $21(61.8)$ & $19(52.8)$ & \\
\hline BMI $\left(\mathrm{kg} / \mathrm{m}^{2}\right)$, mean \pm SD & $24.0 \pm 3.6$ & $24.7 \pm 3.6$ & $24.7 \pm 3.4$ & 0.654 \\
\hline Cigarette smoking, $n(\%)$ & $5(14.3)$ & $4(11.8)$ & $3(8.3)$ & 0.570 \\
\hline Alcohol intake, $n(\%)$ & $12(34.3)$ & $14(41.2)$ & $12(33.3)$ & 0.765 \\
\hline ASA status, $n(\%)$ & & & & 0.657 \\
\hline I & $34(97.1)$ & $34(100)$ & $36(100)$ & \\
\hline II & $1(2.9)$ & $0(0.0)$ & $0(0.0)$ & \\
\hline \multicolumn{5}{|l|}{ Comorbidities, $n(\%)$} \\
\hline Hypertension & $3(8.6)$ & $4(11.8)$ & $6(16.6)$ & 0.706 \\
\hline Diabetes & $3(8.6)$ & $5(14.7)$ & $5(13.9)$ & 0.810 \\
\hline Chronic kidney disease & $0(0.0)$ & $0(0.0)$ & $1(2.8)$ & 1.0 \\
\hline Chronic liver disease & $1(2.9)$ & $1(2.9)$ & $1(2.8)$ & 1.0 \\
\hline Cardiovascular disease & $1(2.9)$ & $2(5.9)$ & $5(13.9)$ & 0.270 \\
\hline Transient cerebral ischemia & $1(2.9)$ & $0(0.0)$ & $1(2.8)$ & 0.820 \\
\hline \multicolumn{5}{|l|}{ Baseline vital sign, mean $\pm S D$} \\
\hline Systolic blood pressure (mm Hg) & $120.0 \pm 11.8$ & $122.8 \pm 13.9$ & $124.0 \pm 13.7$ & 0.438 \\
\hline Diastolic blood pressure ( $\mathrm{mm} \mathrm{Hg}$ ) & $70.2 \pm 9.2$ & $72.7 \pm 9.1$ & $75.0 \pm 8.2$ & 0.079 \\
\hline Heart rate (/min) & $71.2 \pm 11.2$ & $74.1 \pm 12.2$ & $74.3 \pm 10.7$ & 0.450 \\
\hline $\mathrm{O}_{2}$ saturation $(\%)$ & $97.6 \pm 1.5$ & $97.6 \pm 1.5$ & $97.4 \pm 1.7$ & 0.835 \\
\hline
\end{tabular}

ASA, American Society of Anesthesiologists; BMI, body mass index; SD, standard deviation. 


\section{RESULTS}

\section{Baseline characteristics}

Between October and November 2018, 105 patients who underwent sedative endoscopic examination were enrolled. Of these patients, 35 in the $\mathrm{M}+\mathrm{M}$ group, 34 in the $\mathrm{M}+\mathrm{P}$ group, and 36 in the $\mathrm{M}+\mathrm{E}$ group were considered in the final analysis. The mean age of all patients was $55.8 \pm 6.9$ years of age, and there were 47 (44.8\%) male patients. Among groups, age, sex, BMI, ASA status, and histories of smoking, alcohol, and comorbidities were not significantly different. Baseline vital signs of systolic blood pressure, diastolic blood pressure, HR, and $\mathrm{O}_{2}$ saturation were also not significantly different between the groups. Demographic data are shown in Table 1.

\section{Procedure- and sedation-related outcomes}

The outcomes related to the procedure and sedation are presented in Table 2. The mean time to sedation was $2.6 \pm 0.6$ to $3.2 \pm 1.8$ minutes, and the mean total procedure time was $6.0 \pm 1.2$ to $6.5 \pm 2.1$ minutes; thus, there was no significant difference among the groups. Most patients were administered maintenance sedative one or two times during endoscopic examination, although, in the $\mathrm{M}+\mathrm{M}$ group, four patients were administered sedatives more than three times. Satisfaction of patients and endoscopists was not significantly different among the groups. Mean recovery time of patients in the $\mathrm{M}+$ M group was $60.7 \pm 28.8$ minutes, which was significantly longer than that in either the $\mathrm{M}+\mathrm{P}$ group $(38.5 \pm 21.3$ minutes) or $\mathrm{M}+\mathrm{E}$ group (49.4 \pm 27.9 minutes).

\section{Adverse events related to sedation}

Major adverse events such as endotracheal intubation, permanent neurologic impairment, or death did not occur. As shown in Table 3, overall cardiovascular adverse events were

Table 2. Procedure- and Sedation-Related Outcomes

\begin{tabular}{|c|c|c|c|c|}
\hline & $\begin{array}{c}M+M \text { group } \\
(n=35)\end{array}$ & $\begin{array}{c}\text { M + P group } \\
(n=34)\end{array}$ & $\begin{array}{c}M+\text { E group } \\
(n=36)\end{array}$ & $p$-value \\
\hline Time to sedation $^{\text {a) }}$, mean $\pm S D$, min & $3.2 \pm 1.8$ & $2.9 \pm 1.0$ & $2.6 \pm 0.6$ & 0.079 \\
\hline Total procedure time ${ }^{b}$, mean $\pm S D$, min & $6.5 \pm 2.1$ & $6.4 \pm 1.4$ & $6.0 \pm 1.2$ & 0.312 \\
\hline Recovery time $^{c)}$, mean $\pm S D$, min & $60.7 \pm 28.8$ & $38.5 \pm 21.3$ & $49.4 \pm 27.9$ & 0.003 \\
\hline \multicolumn{5}{|l|}{ Administration of maintenance sedative } \\
\hline Number of administrations, $n$ (\%) & & & & 0.095 \\
\hline One & $24(68.6)$ & $22(64.7)$ & $31(86.1)$ & \\
\hline Two & $7(20.0)$ & $12(35.3)$ & $5(13.9)$ & \\
\hline More than three & $4(11.4)$ & $0(0.0)$ & $0(0.0)$ & \\
\hline \multicolumn{5}{|l|}{ Time of administration ${ }^{\mathrm{d})}$} \\
\hline First, mean $\pm S D$, min & $2.8 \pm 0.9$ & $2.5 \pm 0.7$ & $2.5 \pm 0.7$ & 0.089 \\
\hline Second, mean $\pm S D$, min & $5.2 \pm 1.2$ & $4.4 \pm 1.3$ & $4.8 \pm 1.3$ & 0.359 \\
\hline Third, mean $\pm \mathrm{SD}$, min & $6.5 \pm 0.6$ & N/A & N/A & \\
\hline \multicolumn{5}{|l|}{ Satisfaction } \\
\hline Patients, $n(\%)$ & & & & 0.288 \\
\hline Dissatisfied (0-3) & $0(0.0)$ & $0(0.0)$ & $1(2.8)$ & \\
\hline Ordinary (4-6) & $2(5.7)$ & $0(0.0)$ & $0(0.0)$ & \\
\hline Satisfied (7-10) & $33(94.3)$ & $34(100)$ & $35(97.2)$ & \\
\hline Endoscopists, $n(\%)$ & & & & 0.164 \\
\hline Dissatisfied (0-3) & $0(0.0)$ & $0(0.0)$ & $4(11.1)$ & \\
\hline Ordinary (4-6) & $9(25.7)$ & $10(29.4)$ & $8(22.2)$ & \\
\hline Satisfied (7-10) & $26(74.3)$ & $24(70.6)$ & $24(66.7)$ & \\
\hline
\end{tabular}

N/A, not available; SD, standard deviation.

a) Time interval between initial administration of sedative and insertion of the endoscope.

b) Time interval from insertion to removal of the endoscope.

c) Time interval between removal of the endoscope and full-awaken state of the patient (Aldrete score of 10).

${ }^{\mathrm{d})}$ Time interval from initial administration of sedative to administration of maintenance drug. 
Table 3. Adverse Events Related to Sedation

\begin{tabular}{|c|c|c|c|c|}
\hline & $\begin{array}{c}M+\text { M group } \\
(n=35)\end{array}$ & $\begin{array}{c}M+\text { P group } \\
(n=34)\end{array}$ & $\begin{array}{c}M+\text { E group } \\
(n=36)\end{array}$ & $p$-value \\
\hline Overall cardiovascular adverse events, $n$ (\%) & $8(22.9)$ & $5(14.7)$ & $6(16.7)$ & \\
\hline Tachycardia & $6(17.1)$ & $3(8.8)$ & $5(13.9)$ & 0.634 \\
\hline Bradycardia & $0(0.0)$ & $0(0.0)$ & $0(0.0)$ & 1.0 \\
\hline Transient hypotension & $2(5.7)$ & $2(5.9)$ & $1(2.8)$ & 0.740 \\
\hline Arrhythmia & $0(0.0)$ & $0(0.0)$ & $0(0.0)$ & 1.0 \\
\hline Overall respiratory adverse events, $n(\%)$ & $1(2.8)$ & $3(8.8)$ & $4(11.1)$ & 0.434 \\
\hline \multicolumn{5}{|l|}{ Myoclonus, $n(\%)$} \\
\hline Occurrence & $0(0.0)$ & $0(0.0)$ & $3(8.3)$ & 0.105 \\
\hline
\end{tabular}
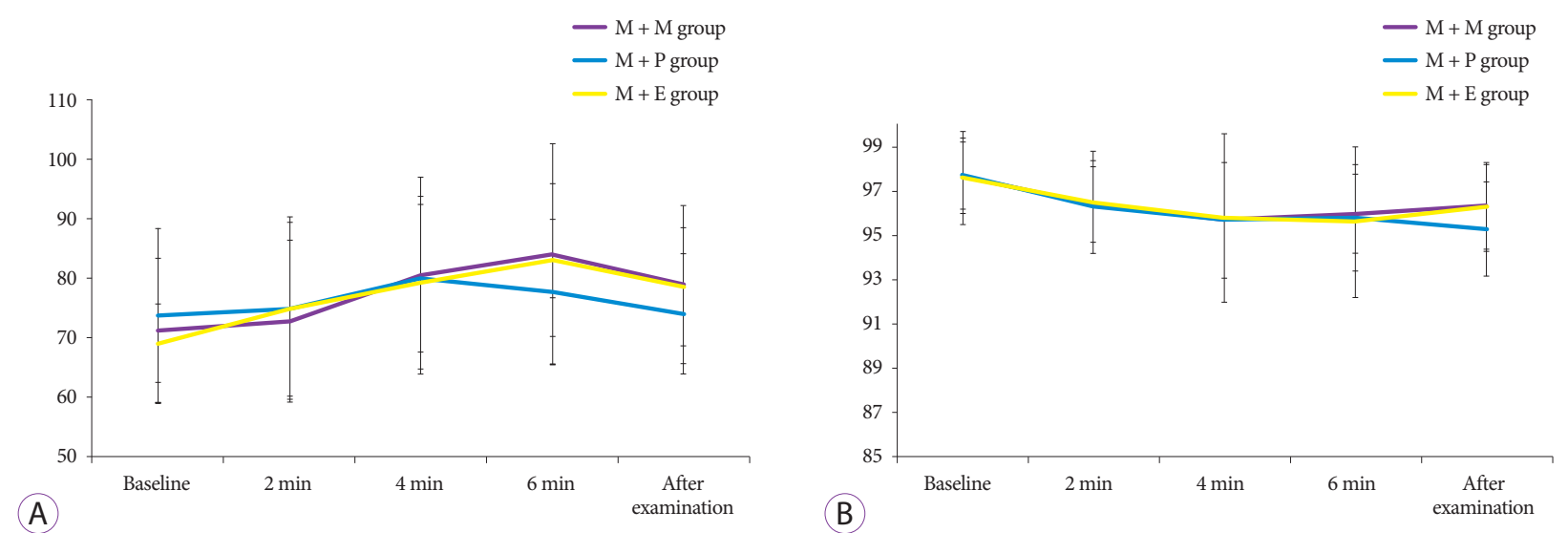

Fig. 1. Changes in heart rate $(A)$ and oxygen saturation $(B)$ of each group at every 2 minutes from baseline to after the examination.

identified in eight patients $(22.9 \%)$ in the $\mathrm{M}+\mathrm{M}$ group, five patients (14.7\%) in the $\mathrm{M}+\mathrm{P}$ group, and six patients (16.7\%) in the $\mathrm{M}+\mathrm{E}$ group. The occurrence of tachycardia, bradycardia, transient hypotension, and arrhythmia was not significantly different among the groups. Overall respiratory adverse events, such as desaturation $\left(\mathrm{O}_{2}\right.$ saturation $\left.<90 \%\right)$, were also not significantly different among the groups, and all patients with desaturation recovered after oxygen was supplied. The graphs in Fig. 1. show the changes in HR and oxygen saturation of each group at every 2 minutes from baseline to after the examination.

\section{Analysis of factors associated with adverse events related to sedation}

We used logistic regression models to analyze the factors triggering cardiovascular and respiratory events (Table 4). After adjusting for potential confounding factors of age, sex, BMI, smoking, alcohol intake, and total procedure time, the overall incidence of cardiovascular events was not different among the groups (odds ratio of midazolam to etomidate, 2.96; 95\% confidence interval [CI], 0.68-12.94; $p=0.150$ vs. odds ratio of propofol to etomidate, 0.78 ; $95 \%$ CI, 0.16-3.89; $p=0.762$ ). Further, the overall incidence of respiratory events did not differ among the groups (odds ratio of midazolam to etomidate, 0.12 ; $95 \%$ CI, $0.01-1.59 ; p=0.108$ vs. odds ratio of propofol to etomidate, 0.52 ; 95\% CI, $0.09-2.88$; $p=0.453$ ). In these analyses, use of etomidate was not found to be an independent risk factor compared with propofol or midazolam for overall cardiovascular and respiratory adverse events. 
Table 4. Factors Associated with Adverse Events Related to Sedation

\begin{tabular}{|c|c|c|c|c|}
\hline & \multicolumn{2}{|c|}{ Overall cardiovascular adverse events } & \multicolumn{2}{|c|}{ Overall respiratory adverse events } \\
\hline & OR $(95 \% \mathrm{CI})$ & $p$-value & OR $(95 \% \mathrm{CI})$ & $p$-value \\
\hline Age, yr & $1.02(0.93-1.11)$ & 0.730 & $0.93(0.82-1.05)$ & 0.219 \\
\hline \multicolumn{5}{|l|}{ Sex } \\
\hline Male & 1 & & 1 & \\
\hline Female & $1.65(0.37-7.29)$ & 0.511 & $15.73(0.69-359.76)$ & 0.084 \\
\hline BMI & $1.22(1.02-1.46)$ & 0.030 & $0.96(0.74-1.25)$ & 0.746 \\
\hline Alcohol & $3.03(0.77-11.96)$ & 0.113 & $0.48(0.05-4.99)$ & 0.541 \\
\hline Smoking & $0.85(0.29-2.46)$ & 0.758 & $2.98(0.39-22.93)$ & 0.295 \\
\hline Total procedure time & $1.10(0.78-1.55)$ & 0.600 & $1.17(0.62-2.20)$ & 0.635 \\
\hline \multicolumn{5}{|l|}{ Sedative } \\
\hline Etomidate & 1 & & 1 & \\
\hline Midazolam & $2.96(0.68-12.94)$ & 0.150 & $0.12(0.01-1.59)$ & 0.108 \\
\hline Propofol & $0.78(0.16-3.89)$ & 0.762 & $0.52(0.09-2.88)$ & 0.453 \\
\hline
\end{tabular}

BMI, body mass index; $\mathrm{CI}$, confidence interval; $\mathrm{OR}$, odds ratio.

\section{DISCUSSION}

Etomidate has few effects on the contractility of cardiac muscle; therefore, it triggers the least amount of variation in hemodynamics of intravenous anesthetics. In addition, it induces less respiratory depression than propofol. Owing to these advantages, etomidate has proved useful for general anesthesia induction in patients with hemodynamic instability. ${ }^{22}$ Recent studies have signaled the safety and feasibility of etomidate for use in the sedation of patients undergoing complex endoscopic procedures, including endoscopic retrograde cholangiopancreatography and endoscopic ultrasonography. ${ }^{19,21}$ A prospective, randomized trial demonstrated that the combination of etomidate and midazolam resulted in fewer cardiopulmonary adverse events and a similar efficacy to that of the combination of propofol and midazolam used for screening colonoscopies in elderly patients. ${ }^{20}$ However, there are few studies on the efficacy and safety of etomidate as a maintenance medication after induction of sedation in endoscopy. In this study, we assessed the efficacy and safety of etomidate compared with propofol or midazolam for the maintenance of sedation during upper gastrointestinal endoscopy. We identified etomidate for maintenance, after induction with midazolam, as a good candidate for sedation during upper gastrointestinal endoscopy.

As shown in Table 3 , the incidence of overall cardiovascular and respiratory adverse events in the $\mathrm{M}+\mathrm{E}$ group was similar to that in both the $\mathrm{M}+\mathrm{P}$ and $\mathrm{M}+\mathrm{M}$ groups. In multivariate logistic regression analysis, the use of etomidate was not a significant factor affecting overall cardiovascular and respiratory adverse events compared with midazolam or propofol. Unexpectedly, myoclonus onset occurred in only three patients $(8.3 \%)$ treated with etomidate, whereas the incidence of myoclonus has been reported as $20 \%$ to $45 \%$ in previous studies. ${ }^{6,8}$ This difference may be caused by pretreatment with midazolam before administration of etomidate. Several studies have shown that pretreatment with midazolam reduced the incidence of etomidate-induced myoclonus. ${ }^{8,23}$ Etomidate has a relatively shorter action duration time (3-5 minutes) than propofol (5-10 minutes) or midazolam (15-60 minutes); therefore, use of etomidate may be a more favorable option regarding recovery time from adverse events. ${ }^{24}$

The sedative efficacy of etomidate for maintenance after induction with midazolam was comparable with that of propofol or midazolam. Procedure- and sedation-related outcomes, including time to sedation, total procedure time, and number of administrations, were not significantly different among the groups. The satisfaction of patients and endoscopists were not significantly different among the groups, although one patient in the $\mathrm{M}+\mathrm{E}$ group and four patients in the $\mathrm{M}+\mathrm{E}$ group reported dissatisfaction.

This study has some limitations. First, this study was performed retrospectively. Therefore, the results of this study inevitably involve selective bias. However, we attempted to minimize any bias by having a single researcher manage all data. Second, the time of sedative administration for maintenance was not the same in all patients (as shown in Table 2). The first administration of midazolam for maintenance was 
relatively later than that of propofol or etomidate, because we did not set the timing of the first administration of the sedative for maintenance, but instead selected approximately 2-3 minutes after the induction sedative. However, the mean time of first administration of sedative for maintenance was not significantly different among the groups. Third, there may be difficulties in generalizing these results because this study was performed in a single medical center and included a relatively small number of patients. Fourth, we measured the post-procedure satisfaction using the visual analog scale; therefore, the assessment of satisfaction of patients or endoscopists may not have been objective.

In conclusion, our study showed that use of etomidate for maintenance after induction of midazolam was not inferior to the use of propofol or midazolam, considering the efficacy and safety in sedative upper gastrointestinal endoscopy. Further longitudinal studies assessing clinical usefulness of etomidate, including the assessment of cost-effectiveness, will be needed to clarify the strength of etomidate for sedative endoscopy. Based on our results, we expect that etomidate will be a good alternative to conventional sedatives, including propofol and midazolam, for sedation in upper gastrointestinal endoscopy.

Conflicts of Interest

The authors have no financial conflicts of interest.

\section{ORCID}

Jae Hyun Kim: https://orcid.org/0000-0002-4272-8003

Sanghwan Byun: https://orcid.org/0000-0002-4211-7851

Youn Jung Choi: https://orcid.org/0000-0002-2892-7639

Hye Jung Kwon: https://orcid.org/0000-0003-1238-3961

Kyoungwon Jung: https://orcid.org/0000-0002-5324-7803

Sung Eun Kim: https://orcid.org/0000-0002-1835-4830

Moo In Park: https://orcid.org/0000-0003-2071-6957

Won Moon: https://orcid.org/0000-0002-3963-8680

\section{REFERENCES}

1. Abraham NS, Wieczorek P, Huang J, Mayrand S, Fallone CA, Barkun AN. Assessing clinical generalizability in sedation studies of upper GI endoscopy. Gastrointest Endosc 2004;60:28-33.

2. Igea F, Casellas JA, González-Huix F, et al. Sedation for gastrointestinal endoscopy. Endoscopy 2014;46:720-731.

3. Cohen LB, Wecsler JS, Gaetano JN, et al. Endoscopic sedation in the United States: results from a nationwide survey. Am J Gastroenterol 2006;101:967-974.

4. Riphaus A, Geist F, Wehrmann T. Endoscopic sedation and monitoring practice in Germany: re-evaluation from the first nationwide survey 3 years after the implementation of an evidence and consent based nation- al guideline. Z Gastroenterol 2013;51:1082-1088.

5. Erdoes G, Basciani RM, Eberle B. Etomidate--a review of robust evidence for its use in various clinical scenarios. Acta Anaesthesiol Scand 2014;58:380-389.

6. Falk J, Zed PJ. Etomidate for procedural sedation in the emergency department. Ann Pharmacother 2004;38:1272-1277.

7. Guler A, Satilmis T, Akinci SB, Celebioglu B, Kanbak M. Magnesium sulfate pretreatment reduces myoclonus after etomidate. Anesth Analg 2005;101:705-709.

8. Hüter L, Schreiber T, Gugel M, Schwarzkopf K. Low-dose intravenous midazolam reduces etomidate-induced myoclonus: a prospective, randomized study in patients undergoing elective cardioversion. Anesth Analg 2007;105:1298-1302.

9. Conway A, Rolley J, Sutherland JR. Midazolam for sedation before procedures. Cochrane Database Syst Rev 2016;(5):CD009491.

10. Lewis JH, Benjamin SB. Safety of midazolam and diazepam for conscious sedation. J Clin Gastroenterol 1990;12:716-717.

11. Nishizawa T, Suzuki H. Propofol for gastrointestinal endoscopy. United European Gastroenterol J 2018;6:801-805.

12. Mackenzie N, Grant IS. Propofol for intravenous sedation. Anaesthesia 1987;42:3-6.

13. Sasaki T, Tanabe S, Azuma M, et al. Propofol sedation with bispectral index monitoring is useful for endoscopic submucosal dissection: a randomized prospective phase II clinical trial. Endoscopy 2012;44:584-589.

14. Lin OS. Sedation for routine gastrointestinal endoscopic procedures: a review on efficacy, safety, efficiency, cost and satisfaction. Intest Res 2017;15:456-466.

15. Park JH, Kim HJ, Seo JS. Medicolegal review of deaths related to propofol administration: analysis of 36 autopsied cases. Korean J Leg Med 2012;36:56-62.

16. Lee TH, Lee CK, Park SH, et al. Balanced propofol sedation versus propofol monosedation in therapeutic pancreaticobiliary endoscopic procedures. Dig Dis Sci 2012;57:2113-2121.

17. Lee CK, Lee SH, Chung IK, et al. Balanced propofol sedation for therapeutic GI endoscopic procedures: a prospective, randomized study. Gastrointest Endosc 2011;73:206-214.

18. Levitzky BE, Lopez R, Dumot JA, Vargo JJ. Moderate sedation for elective upper endoscopy with balanced propofol versus fentanyl and midazolam alone: a randomized clinical trial. Endoscopy 2012;44:13-20.

19. Kim MG, Park SW, Kim JH, et al. Etomidate versus propofol sedation for complex upper endoscopic procedures: a prospective double-blinded randomized controlled trial. Gastrointest Endosc 2017;86:452-461.

20. Lee JM, Min G, Lee JM, et al. Efficacy and safety of etomidate-midazolam for screening colonoscopy in the elderly: a prospective double-blinded randomized controlled study. Medicine (Baltimore) 2018;97:e10635.

21. Park CH, Park SW, Hyun B, et al. Efficacy and safety of etomidate-based sedation compared with propofol-based sedation during ERCP in lowrisk patients: a double-blind, randomized, noninferiority trial. Gastrointest Endosc 2018;87:174-184.

22. Gelissen HP, Epema AH, Henning RH, Krijnen HJ, Hennis PJ, den Hertog A. Inotropic effects of propofol, thiopental, midazolam, etomidate, and ketamine on isolated human atrial muscle. Anesthesiology 1996;84:397-403.

23. Schwarzkopf KR, Hueter L, Simon M, Fritz HG. Midazolam pretreatment reduces etomidate-induced myoclonic movements. Anaesth Intensive Care 2003;31:18-20.

24. Forman SA. Clinical and molecular pharmacology of etomidate. Anesthesiology 2011;114:695-707. 